\title{
Forward modelling of seismic response from North Sea Chalk
}

\author{
Ole Valdemar Vejbæk and Rasmus Rasmussen
}

Seismic inversion has become a standard tool for porosity prediction in chalk exploration and field development. AVO (amplitude versus offset) processing for fluid prediction is, however, still not widely applied in chalk. Forward modelling may help to assess the value of acquiring these data, as well as support subsequent interpretation. This paper presents a forward modelling tool to simulate seismic response resulting from changes in degree of compaction and fluid contents in profiles. Modelling is carried out with software developed by Norsk Hydro A/S (the Compound Model Builder), where the Geological Survey of Denmark and Greenland has supplied special capabilities to model North Sea Chalk. The forward modelling is illustrated with a seismic line straddling the Dan and Halfdan chalk fields (Fig. 1). Hydrocarbons are found in the uppermost Danian and Maastrichtian chalk where porosity may exceed $30 \%$. Production takes place from wells centred on an anticline in the Dan Field, and although structural closure is lacking for the Halfdan Field, a surprising laterally continuous oil column is found between the two fields (e.g. Jacobsen et al. 1999; Albrechtsen et al. 2001).
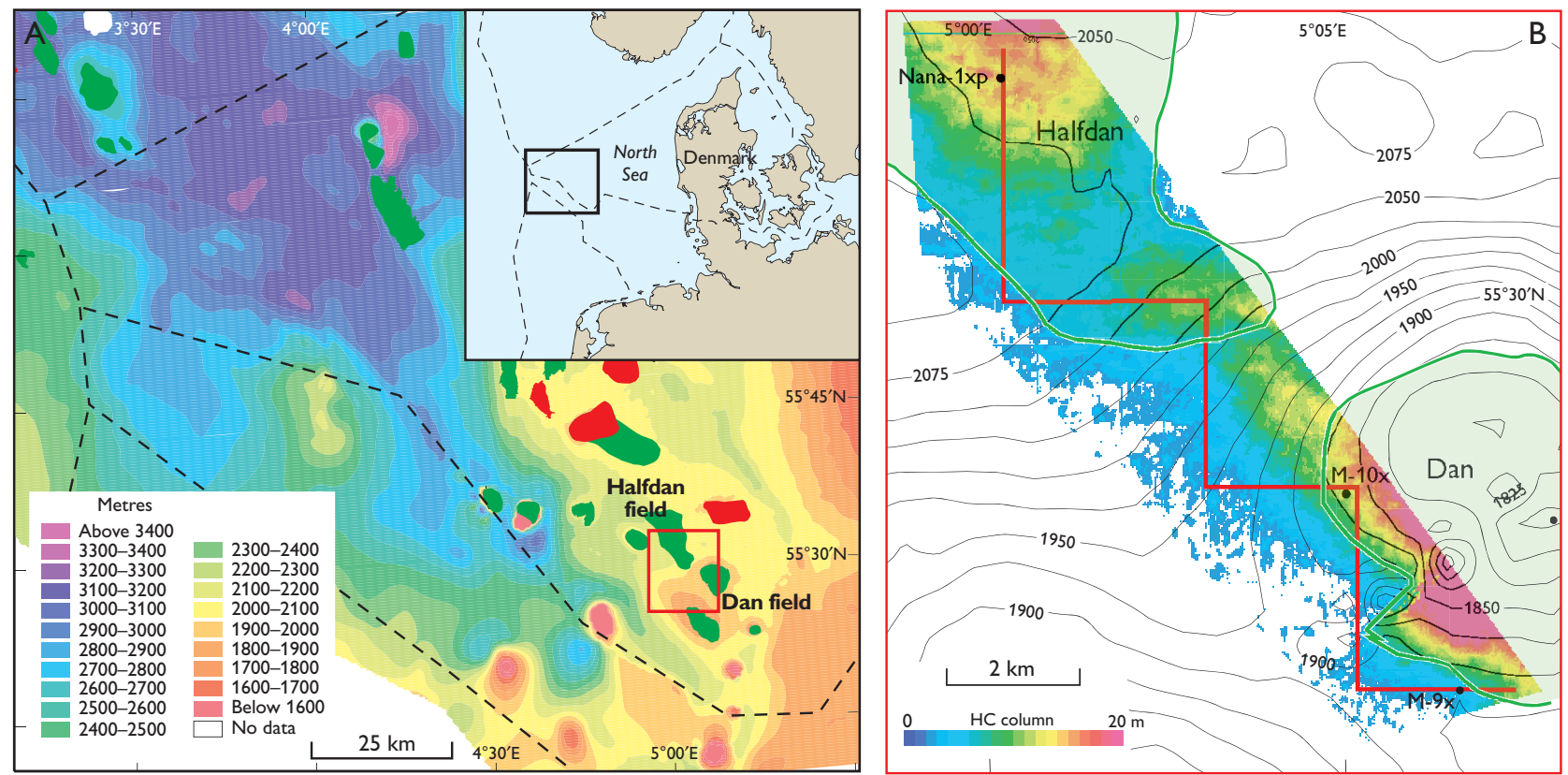

Fig. 1. A: Map showing top chalk depth structure for the Danish North Sea area and location of Dan and Halfdan fields. Producing oil and gas fields are shown in green and red, respectively. B: Location of the simulated seismic line from the Halfdan to the Dan field (see Fig. 3). The zig-zag geometry follows trace and line directions in the 3D seismic survey. Colour bar shows net height of Danian and Maastrichtian hydrocarbon column. Top chalk depth contours in $25 \mathrm{~m}$ interval.

The modelling target is the effect on seismic data of such oil occurrences. The rather subtle impact on rock properties requires very realistic and detailed modelling. Fortunately, the pelagic deep-water origin of the chalk makes it very uniform laterally, such that compaction effects and fluid changes handled by the modelling tool account for lateral seismic changes, whereas well data support vertical changes.

\section{Forward modelling approach}

Prediction of compaction effects starts with modelling porosity change, and subsequently the seismic properties of bulk density and P- and S-wave velocities are calculated. These predictions account for changes in acoustic properties away from wells, as in synclines and anticlines. Empirical compaction laws are applied where excess fluid pressure is accounted for in a simplistic way (Vejbæk et al. in press b). An exponential decay of porosity $(\phi)$ with depth $(z)$ is assumed:

$$
\phi=\phi_{0} \cdot \mathrm{e}^{-\mathrm{a} z}
$$



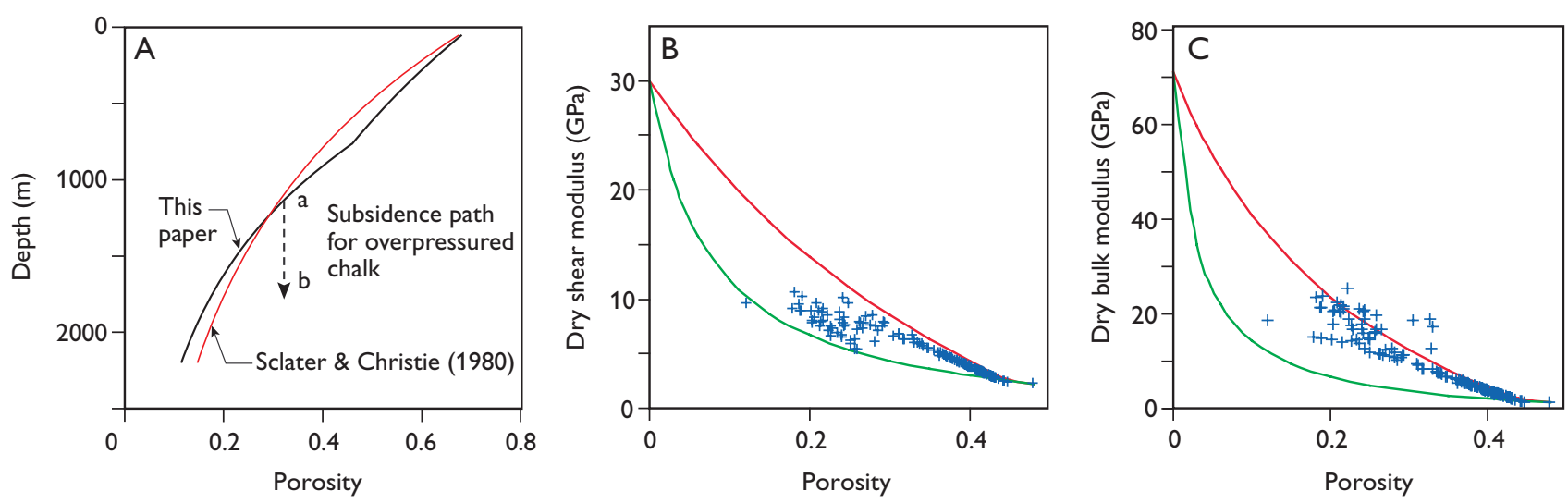

Fig. 2. A: Schematic compaction behaviour of chalk (black curve) with the Sclater and Christie (1980) model (red curve) for comparison. B: Dry shear and $\mathbf{C}$ : bulk moduli for some chalk data. Solid lines are upper (red) and lower (green) modified Hashin-Shtrikman boundaries. Following compaction changes new moduli are estimated by shifting points parallel to these boundaries. Slightly modified from Vejbæk et al. (in press b).

where each layer has a surface porosity $\left(\phi_{0}\right)$ and $a$ is the decay parameter (Sclater \& Christie 1980; Jensen et al. 1985). Further developments to account for overpressure and more complex chalk porosity decay are given by Vejbæk et al. (in press b). Deviation of average porosity from the normal compaction trend is due to overpressure and/or early hydrocarbon invasion which stops porosity decay (Fig. 2A). The method yields good predictions of excess fluid pressures in the absence of hydrocarbon preserving effects. These predictions rely on good calibration of the compaction parameters, and on the presumably very late onset and modest subsequent dissipation of overpressure in the studied region. The chalk compaction trend is based on the revised normal velocity-depth trend of Japsen (1998) converted into a porosity-depth trend (Vejbæk et al. in press b).

The decompaction parameterisation addresses only thick chalk successions and does not account for small-scale variations in porosity as on well logs. Adjusting the surface porosity for each log sample after overpressure correction retains these details. Each sample thus compacts or decompacts along a slightly different porosity decay path. Local-scale variations are thus assumed to be inherited from time of deposition. This causes porosity variations to increase during decompaction and decrease during compaction. This behaviour complies with the general observation that highly reflective chalk often correlates with high porosity (Britze et al. 2000).

Before well data are entered into the model builder, they are normalised to an arbitrarily chosen depth $(2100 \mathrm{~m}$ in the case shown) using the approach described. Following interpolation along the interpreted horizons in the model builder, porosity is then restored to the appropriate depth along the profile. The process honours observed porosity profiles at well sites and accounts for depth changes along the profile.
Following compaction/decompaction, sonic and density logs are corrected. The corrections are based on a modified Hashin-Shtrikman model as proposed by Walls et al. (1998) for Ekofisk Field data (see Vejbæk et al. in press b). The model describes how bulk and shear moduli change with porosity in an interval between zero porosity and a chosen maximum porosity (Fig. 2B, C). Stiffer chalk types plot closer to the modified upper Hashin-Shtrikman (MUHS) model, and softer chalk types plot closer to the lower bounding limit. During compaction, changes in bulk moduli are adjusted according to the modified Hashin-Shtrikman model.

Changes in compaction cause changes in hydrocarbon saturation as given by the saturation model. Calculation of the fluid effects involves modelling of the saturation distribution and resulting effects on seismic properties of the rock.

Hydrocarbon saturation is modelled with the equivalent radius method (EQR; Engstrøm 1995). This model yields drainage equilibrium saturation based on estimates of capillary pressure in relation to capillary entry pressure. The capillary entry pressures in the chalk are considerable, and distances between free water levels (where oil and water pressure are equal) and the oil-water contacts are usually measured in tens of metres. Hydrocarbon saturation functions for Danian and Maastrichtian chalk differ slightly, with Danian chalk being less favourable. Changes in acoustic properties caused by changes in fluid content are calculated by fluid substitution (Gassmann 1951). The Gassmann theory has been shown to apply to laboratory elastic measurements on chalk and therefore also applies to $\log$ and seismic data (Fabricius et al. 2002; Japsen et al. 2002, 2005).

All the compaction changes and the seismic property calculation including fluid effects are combined into one routine in the Compound Model Builder. In order to investigate various scenarios of hydrocarbon distribution, editing of the free water level (FWL) is sufficient. 

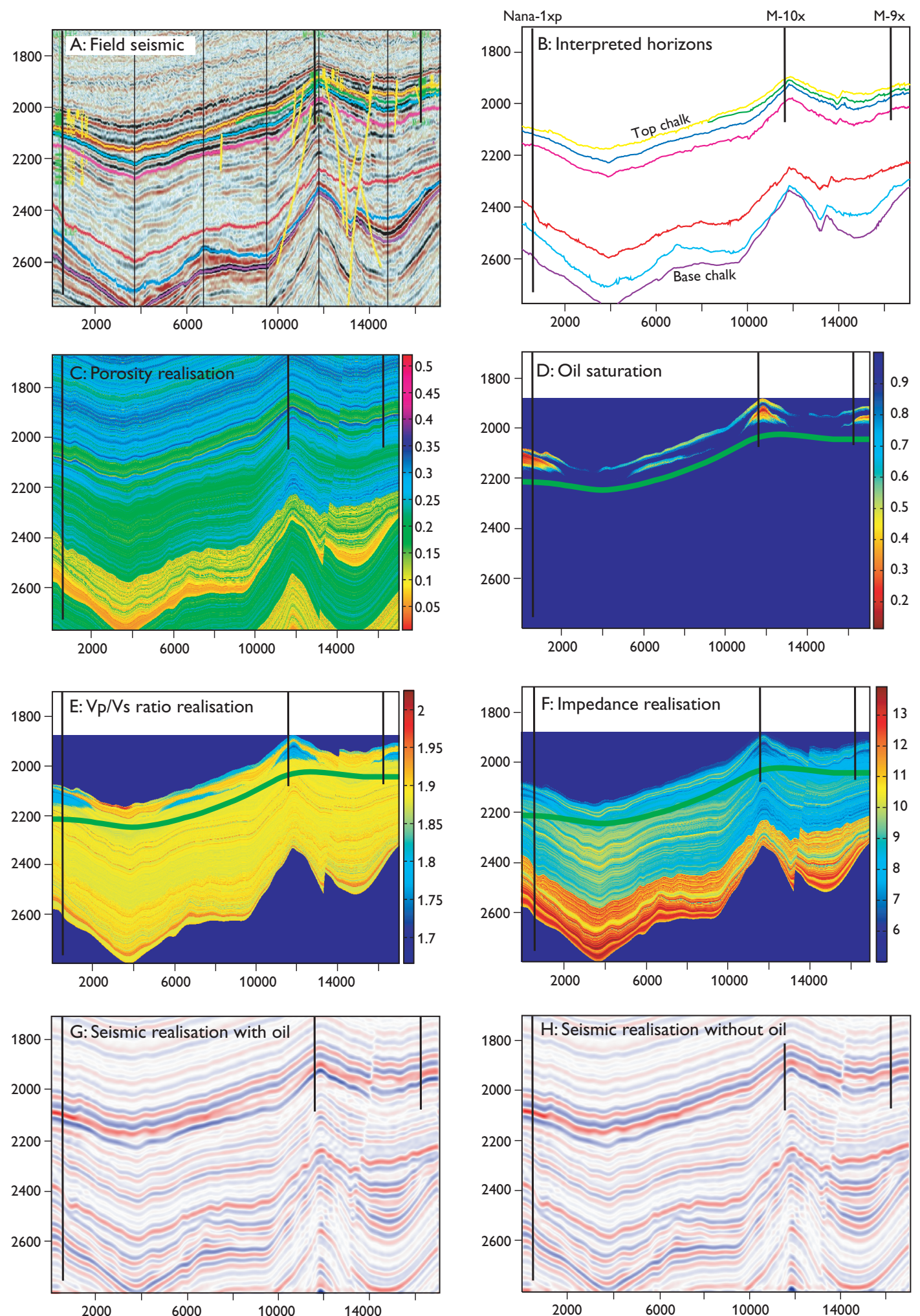

Fig. 3. A: Original seismic section; see Fig. 1 for location. B: Depth profile of the interpreted horizons. The lower two thirds of the chalk is based only on the Nana-1xp well. C: Reconstructed porosity section. Note lateral porosity variation outside well control. D: Calculated water saturation profile. The free water level (green line) controls the calculated oil columns (cf. Fig. 1B). E: Calculated Vp/Vs ratio. Oil causes a reduced Vp/Vs ratio. F: Calculated acoustic impedance profile. The porosity dependency is clear, but only a weak hydrocarbon effect is present. G: Forward modelled seismic response with the oil content as in D. H: Forward modelled seismic response with only water. A subtle amplitude increase may be noted at top chalk level. Vertical and horizontal scales are in metres. 


\section{Example from the Dan and Halfdan fields}

Seven horizons were interpreted in the chalk in the studied case. Interpolation of rock properties occurs along these horizons. The deeper two thirds of the chalk succession has only been penetrated by the Nana-1xp well, whereas the upper third (and shallower horizons) have been drilled by all wells. Properties are therefore only interpolated in the shallower parts, whereas deeper parts are extrapolated from the Nana1xp well (Fig. 3B). In addition an FWL (based on Albrechtsen et al. 2001) is included to show fluid effects (Fig. 1). The resulting peculiar oil saturation variations (Fig. 3C) are due to the zig-zag course of the profile. Depth dependent changes in porosity beyond well control are obvious and are reflected in the acoustic impedance profile (Fig. 3D, E). Oil effects on impedance are insignificant (Fig. 3C, E), whereas a clear fluid response is seen in the $\mathrm{Vp} / \mathrm{Vs}$ ratio profile (Fig. 3F). Fluid effects are thus predicted to be detectable with AVO processing from which the $\mathrm{Vp} / \mathrm{Vs}$ ratio is obtained. However, due to the non-linear fluid effect on the $\mathrm{Vp} / \mathrm{Vs}$ ratio, it is not well suited for monitoring reservoir depletion in real data (timelapse seismic) which is affected by noise (e.g. Japsen et al. 2004, 2005; Vejbæk et al. in press b). The most significant $\mathrm{Vp} / \mathrm{Vs}$ response occurs in the oil saturation interval of $0 \%$ to $30 \%$, whereas the response change from typical residual oil saturation of around $30 \%$ to full saturation is negligible. The selective fluid predicting capability of $\mathrm{Vp} / \mathrm{Vs}$ (or Poisson ratio) is still of considerable value for reservoir mapping because chalk reservoirs generally are affected by tilted fluid contacts that may be difficult to predict (e.g. Vejbæk et al. in press a). The two forward models of the reflection seismic response (Fig. 3G, H) demonstrate the subtle fluid effect on seismic response. In Fig. $3 \mathrm{H}$ all oil has been replaced by water. This causes a slight increase in top chalk reflectivity.

\section{Conclusions}

The applied compaction model reproduces changes in seismic reflectivity similar to those observed. Hydrocarbons are shown to have a subtle impact on standard seismic response in chalk. Direct oil identification from reflection data is unlikely in the absence of abnormally preserved porosity by early hydrocarbon invasion. However, direct identification of hydrocarbons based on the $\mathrm{Vp} / \mathrm{Vs}$ ratio (or Poisson ratio) derived from amplitude versus offset analysis may be possible. In some cases, impedance data may show fluid effects. In general the fluid effects are subtle and confirmation by forward modelling requires models to be as realistic as possible.

\section{References}

Albrechtsen, T., Andersen, S.J., Dons, T., Engstrøm, F., Jørgensen, O. \& Sørensen, F.W. 2001: Halfdan: developing non-structurally trapped oil in North Sea Chalk. Society of Petroleum Engineers Paper 71322, 14 pp.

Britze, P., Nielsen, E.B., Dahl, N. \& Haug, S. 2000: North Sea chalk porosity resolved by integration of seismic reflectivity and well log data. EAGE/SAID Conference, Paris, France, 6-8 November, 2000. Abstracts. Paper B30, 7 pp.

Engstrøm, F. 1995: A new method to normalize capillary pressure curves. International Symposium of the Society of Core Analysts, San Francisco, USA, 1995. Proceedings. Paper 9535, 12 pp.

Fabricius, I.L., Mavko, G., Mogensen, C. \& Japsen, P. 2002: Elastic moduli of chalk as a reflection of porosity, sorting and irreducible water saturation. Society of Exploration Geophysicists Technical Programme and Expanded Abstracts 21, 1903-1906.

Gassmann, F. 1951: Elastic waves through a packing of spheres. Geophysics 16, 673-685.

Jacobsen, N.L., Engstrøm, F., Uldall, A. \& Petersen, N.W. 1999: Delineation of hydrodynamic/geodynamic trapped oil in low permeability chalk. Society of Petroleum Engineers Paper 56514, 10 pp.

Japsen, P. 1998: Regional velocity-depth anomalies, North Sea Chalk: a record of overpressure and Neogene uplift and erosion. American Association of Petroleum Geologists Bulletin 82, 2031-2074.

Japsen, P., Høier, C., Rasmussen, K.B., Fabricius, I.L., Mavko, G. \& Pedersen, J.M. 2002: Effects of fluid substitution on ultrasonic velocities in chalk plugs, South Arne Field, North Sea. Society of Exploration Geophysicists Technical Programme and Expanded Abstracts 21, 1881-1884.

Japsen, P., Bruun, A., Fabricius, I.L., Rasmussen, R., Vejbæk, O.V., Pedersen, J.M., Mavko, G., Mogensen, C. \& Høier, C. 2004: Influence of porosity and pore fluid on acoustic properties of chalk: AVO-response from oil, South Arne Field, North Sea. Petroleum Geoscience 10, 319-330.

Japsen, P., Bruun, A., Fabricius, I.L. \& Mavko, G. 2005: Identification of hydrocarbons in chalk reservoirs from surface seismic data; South Arne Field, North Sea. Geological Survey of Denmark and Greenland Bulletin 7, xx-yy (this volume)

Jensen, P.K., Holm, L. \& Thomsen, E. 1985: Modelling burial history, temperature and maturation. In: Thomas, B.M. et al. (eds): Petroleum geochemistry in exploration of the Norwegian Shelf, 145-152. London: Graham \& Trotman.

Sclater, J.G. \& Christie, P.A.F. 1980: Continental stretching: an explanation of the post-mid-Cretaceous subsidence of the central North Sea Basin. Journal of Geophysical Research 85, 3711-3739.

Vejbæk, O.V., Frykman, P., Bech, N. \& Nielsen, C.M. in press a: The history of hydrocarbon filling of Danish chalk fields. In: Doré, A.G. \& Vinning, B. (eds): Petroleum geology: North-West Europe and global perspectives: Proceedings of the 6th Petroleum Geology Conference. London: Geological Society.

Vejbæk, O.V., Rasmussen, R., Japsen, P., Bruun, A., Pedersen, J.M., Marsden, G. \& Fabricius, I.L. in press b: Modelling seismic response from North Sea chalk reservoirs resulting from changes in burial depth and fluid saturation. In: Doré, A.G. \& Vinning, B. (eds): Petroleum geology: North-West Europe and global perspectives: Proceedings of the 6th Petroleum Geology Conference. London: Geological Society.

Walls, J.D., Dvorkin, J. \& Smith, B.A. 1998: Modeling seismic velocity in Ekofisk Chalk. Society of Exploration Geophysicists Technical Programme and Expanded Abstracts 17, 1016-1019. 